\title{
A mí de vos no me trata ni usted ni nadie. Sistemas e historia de las formas de tratamiento en la lengua española en América:
}

Bertolotti, Virginia. (2015). A mí de vos no me trata ni usted ni nadie. Sistemas e historia de las formas de tratamiento en la lengua española en América. Ciudad de México: Universidad Nacional Autónoma de México y Universidad de la República de Uruguay. ISBN 978-607-02-6627-0 (UNAM) 978-9974-0-1224-0 (Universidad de la República). 483 pp. Precio: € 17,26.- U\$A 18,35.-

Reviewed by Verónica Orellano, Facultad de Filosofía, Humanidades y Artes, Universidad Nacional de San Juan, Ignacio de la Roza 235 (0) 5400, San Juan, Argentina,

E-mail: iorellan@ffha.unsj.edu.ar

DOI 10.1515/soprag-2017-0010

Una buena noticia para los interesados en la variación hispanoamericana de los sistemas lingüísticos de tratamiento, llega con el libro A mí de vos no me trata ni usted ni nadie. Sistemas e historia de las formas de tratamiento en la lengua española en América, de Virginia Bertolotti.

El valioso tratado incluye una Primera Parte, "El tratamiento y los sistemas de tratamiento del español en América” con la exposición de teorías acerca del tratamiento, y el análisis de las diversas formas pronominales y verbales que caracterizan la relación locutor-alocutario en el español hablado en América. La Segunda Parte, "Historia de los sistemas de tratamiento en el español preamericano y americano”, despliega una mirada diacrónica sobre el origen de estas formas de tratamiento y su desarrollo en el contexto americano, haciendo especial hincapié en el estudio del voseo. La Tercera Parte, "Diacronía de los verbos y pronombres alocutivos en el español en Uruguay”, desarrolla los tratamientos vigentes en el español uruguayo del siglo XIX, acerca de los cuales se consigna el corpus en ANEXOS.

En la Primera Parte, la perspectiva teórica y descriptiva de los estudios del tratamiento se caracteriza por su amplitud, dado que considerará tanto paradigmas nominales como verbales que señalan, no sólo personas gramaticales, sino modos de marcar posiciones sociales, culturales y de vínculo psicológico 
entre locutor y alocutario. Aportaciones generales como Brown y Gilman (1960) y de estudiosos locales, como Fontanella de Weinberg (1999), son recorridas con espíritu crítico y aplicación de una contemporánea asunción acerca del carácter continuo de las oposiciones formales en su valor de uso. Valga como ejemplo, la reformulación de los valores que asumen las formas-t (correspondientes a la segunda persona) signadas en general con el meaning de acercamiento, versus las formas-v (correspondientes a tercera persona) con el significado contrario. La riqueza de matices que la lengua permite expresar está aquí considerada (Bertolotti 2015, pp. 20-27).

Sin embargo, en algunas afirmaciones posteriores de la obra se manifestará un marco teórico que separa el valor pragmático de las formas, del semántico. Por ejemplo, después de citar varios casos en los que hablantes de Chile se quejan del trato ofensivo de vos ("airadas palabras", "injurias", "tratar mal” en Bertolotti 2015, p. 118), la autora afirma que tales usos "no prueban de manera alguna que vos fuera una manera insultante, aunque usarla impropiamente podía formar parte de una actitud insultante" (Bertolotti 2015, p. 119). En la situación de habla, el ítem vos acompaña la intención del hablante y por eso debe suponerse en él algún valor significativo compatible con "insulto u ofensa" coherente con el contexto, sea cual sea su extensión diatópica, diafásica o diastrática. La coherencia meaning-message es el principio explicativo fundamental de la teoría lingüística que la autora está citando (entre otros, García, 1999 y 2004; y García et alii, 1990; De Jonge y Niewenhuijsen, 2009).

En el capítulo referido a la situación sincrónica de la variación en el ámbito americano, se refiere el conocido modelo triádico tú-vos-usted, a la vez que se despliega su distribución.

Particularmente interesantes en este capítulo son el cuadro y mapa actuales de la distribución del fenómeno estrella del tratamiento en español americano, el voseo, en países -y regiones internas a un país- en que vuelve a quedar clara la variación diatópica del fenómeno. Desigualmente distribuido en regiones, con predominio del cono sur de América del Sur, se registra que -salvo excepcionesno se corresponde con diferencias diastráticas (Bertolotti 2015, pp. 38-39).

En un detallado cuadro ofrecido en las páginas 44-45, se presentan las diferentes formas verbales que asume el voseo, a partir del cual la autora registra lagunas informativas y/o contradicciones entre las afirmaciones de autores precedentes como José Pedro Rona y constataciones más recientes que, en el contexto de este estudio, no pueden dilucidarse.

Fenómenos menos estudiados como el uso de usted y de su merced ocupan igualmente la curiosidad de la autora, tanto en esta parte como en las dos restantes.

En la Segunda Parte destinada a la historia de los sistemas de tratamiento, la autora analiza extensamente la evolución de las formas pronominales, y de 
modo más breve la variación de formas verbales, señalando vacíos en el estado de conocimiento en varios aspectos, como es la diacronía y sincronía de los usos plurales en el continente.

Bertolotti estudia los usos del español peninsular del siglo XV que llegaron a América, con un sistema de parámetros como: familiaridad o no, intra- o extragrupalidad, reverencialidad o no, deferencialidad o no. A partir de estas diferencias podrá afirmar que en los siglos XVI y XVII en América, el uso de vos singular habría perdido su carácter de marcador de clase social, y señalaría más bien al alocutario como una persona externa al grupo que no merece un trato especialmente respetuoso (Bertolotti 2015, pp. 110-117).

Con las herramientas teóricas comentadas en párrafo anterior, la autora objeta explicaciones precedentes como la adopción de vos por la supuesta "hidalguización" de los conquistadores - tesis sostenida por Rosenblat- y su contraria, la difusión de vos por el valor despectivo de este uso hacia los naturales americanos -hipótesis originaria de Rufino Cuervo (Bertolotti 2015, pp. 112-114).

Respecto de la evolución del voseo en el ámbito rioplatense, los razonamientos de la autora la llevan a disentir con asertos de Fontanella de Weinberg respecto a los siglos XVI y XVII (según los cuales vos habría adoptado un matiz señalador de cercanía entre los hablantes), pero a apoyar a la estudiosa argentina respecto al siglo XIX, donde se registraban usos urbanos versus usos rurales de vos, siendo éstos los más consolidados. Ampliando y precisando estas afirmaciones, Bertolotti sostiene la validez de los parámetros antes formulados, y realiza una explicación de mayor complejidad al incorporar para vos el valor de extra-grupalidad como más consistente.

Como puede verse, el estudio abunda en atinadas reflexiones que reinterpretan conjuntamente los aportes de anteriores estudiosos. Bertolotti es una lectora prolija que hace dialogar teorías y descripciones de datos (Castillo, 1982; García et alii, 1990; De Jonge y Niewenhuijsen, 2009), y concluye coherentemente a partir de ellos, con razonamientos basados en principios muy actuales del variacionismo lingüístico. Efectivamente, algunos tratamientos clásicos acerca de la difusión del voseo en América tendían a generalizar, e ignorar la variabilidad inherente a cualquier etapa de uso de la lengua, por atender al punto de llegada histórico de la diferencia entre usos peninsulares y americanos. Frente a ello, una mayor discriminación de factores hace honor a la complejidad de los hechos estudiados atendiendo a diversas fuentes. Por ejemplo, el análisis y cuadro de "los parámetros que gobernaban el tratamiento pronominal en la región bonaerense a fines del siglo XVIII y durante el siglo XIX" se hace "de acuerdo con los estudios de Fontanella de Weinberg y con la interpretación realizada de alguno de sus ejemplos” (Bertolotti 2015, p. 127). 
Sin embargo, en la nueva interpretación de los valores semánticos de las formas de tratamiento en los Siglos XVI y XVII, el especialista extrañará el análisis cuantitativo de corpus, con lo que se resiente el valor explicativo de las aseveraciones de la autora. Con respecto a los Siglos XVIII y XIX, la situación cambia, dado que se aportan datos analizados por la autora y su grupo (Elizaincín, Malcuori y Bertolotti, 1997) y los relativos a Uruguay que ocupan la Tercera Parte, de los que pueden extraerse certezas.

La Tercera Parte explica los cambios del sistema de tratamiento en Uruguay del siglo XIX, con una síntesis de la tesis doctoral de la autora. Sobre datos extraídos de dos tipos de corpora (el primario de carácter epistolar y el secundario de fuentes literarias y periodísticas), se discriminan dos ámbitos de empleo de formas-t y formas-v, la familia y la sociedad. Se descubre así que el desequilibrio que dará origen al cambio histórico se da mayoritariamente entre personas de igual poder (Bertolotti 2015, p. 206), y cuando vos se vuelva el uso preferido en población urbana juvenil.

Un hallazgo interesantísimo, y corroborado con números, refiere el avance de la forma innovadora en los espacios sintácticos marginales de la oración, como término de preposición (vos frente a tî) y no en función sujeto (Bertolotti 2015, pp. 241-242).

Valioso aporte para la consecución de estudios sobre el tema es la transcripción del corpus de estudio para el caso de Uruguay, que ocupa el Anexo 2 (Bertolotti 2015, pp. 311-480) y respeta estrictamente normas de escritura de cien cartas originales del Siglo XIX en dos etapas, la primera correspondiente al primer cuarto de siglo y la segunda, al último. Su lectura conlleva un repaso de hechos socio-históricos de gran interés para nuestras repúblicas hermanas, a la vez que un curioso testimonio de valores, creencias y costumbres del Siglo XIX. El lenguaje, fiel testigo de vidas pasadas, permite ejemplificar tratamientos notoriamente extensos y ceremoniosos a los destinatarios objeto de deferencia entre íntimos (de padres a hijos y a la inversa; de tíos a sobrinos y a la inversa; de amigos entre sí, y hasta de yerno a suegra), y diferenciarlos de los restantes. Las expresiones "Mi estimado tío y favorecedor" (Bertolotti 2015, p. 353), "Muy señor mío y estimado amigo" (Bertolotti 2015, p. 363), o "Mi amadísima y muy apreciable Consolación” (Bertolotti 2015, p. 383) contrastan icónicamente con la muy escueta fórmula "Señor Máximo Santos" (Bertolotti 2015, p. 395) que precede a un anónimo insultante.

En suma, el que reseñamos es un libro de agradable lectura que conjuga una puesta al día acerca de estudios teóricos y descriptivos acerca del tratamiento y un meduloso análisis del tema referido a Uruguay del siglo XIX, con la aportación de numerosos textos literarios y periodísticos en los que la intuición del escritor capta con agudeza etnográfica y social, el valor de las distintas 
formas. Valga como ejemplo de lo segundo, la extensa cita del dramaturgo argentino Roberto Cossa (Bertolotti 2015, pp. 49-50) que detecta con particular acierto el valor del tuteo para distintas generaciones y situaciones comunicativas en su país.

\section{Referencias bibliográficas}

Bertolotti, V. (2011). Los cambios en la segunda persona del singular durante el siglo XIX en el español del Uruguay. Rosario: Universidad Nacional de Rosario.

Brown, R. \& Gilman, A. (1960). The Pronouns of Power and Solidarity. En Sebeok, T. A. (Ed.), Style in Language (pp. 253-276). Cambridge: MIT Press.

De Jonge, R. \& Niewenhuijsen, D. (2009). Formación del paradigma pronominal de las formas de tratamiento. En Company Company, C. (Dirs.), Sintaxis histórica de la lengua española. Segunda parte: La frase nominal 2 (pp. 1593-1671). México: Fondo de Cultura Económica /Universidad Nacional Autónoma de México.

Del Castillo M., N. (1982). Testimonios del uso de "vuestra merced", "vos" y "tú" en América (1500-1650). Thesaurus 37, 602-644.

Elizaincín, A., Malcuori, M. \& Bertolotti, V. (1997). El español en la Banda Oriental del siglo XVIII. Montevideo: Universidad de la República.

Fontanella de Weinberg, M. B. (1999). Sistemas pronominales de tratamiento usados en el mundo hispánico. En Bosque, I. \& Demonte, V. (Dirs.), Gramática descriptiva de la lengua española (pp. 1401-1425). Madrid: Espasa.

García, E. (1999). Asimetría distribucional como reflejo de congruencia (con)textual. Neuphilologische Mitteilungen 100 (4), 455-470.

García, E, De Jonge, R., Niewenhuijsen, D. \& Lechner, C. (1990). (V)os-(otros): ¿dos y el mismo cambio? Nueva Revista de Filología Hispánica 38, 63-132.

García, E. (2004). ¿Con el rey o con el conde? “Ser” vs. “Estar” en la Crónicas de Pero López de Ayala. Neuphilologische Mitteilungen 105 (4), 453-482. 